\title{
Dentist's Hub Bub - A Cross-Sectional Study on Impact of Long-Term Occupational Noise Exposure on Hearing Potential among Dental Practitioners
}

Jayaprada Reddy Surakanti1 ${ }^{1}$, Vikram Reddy Guntakandla² ${ }^{2}$ Preethi Raga ${ }^{3}$, Vishwaja Uppalapati ${ }^{4}$, Sai Praveena Kunaparaju ${ }^{5}$, Harikumar Vemisetty ${ }^{6}$, Suryakanth Malgikar ${ }^{7}$

1, 4, 5, 6 Department of Conservative Dentistry and Endodontics, Kamineni Institute of Dental Sciences, Narketpally, Nalgonda, Telangana, India. 2, 7 Department of Periodontology, Kamineni Institute of Dental Sciences, Narketpally, Nalgonda, Telangana, India. ${ }^{3}$ Department of ENT, Kamineni Institute of Medical Sciences, Narketpally, Nalgonda, Telangana, India.

\section{ABSTRACT}

\section{BACKGROUND}

Dentists are liable to loss of hearing during dental treatment due to noise exposure. A study was carried out to determine whether or not dental professionals from the Department of Periodontics, Conservative Dentistry and Endodontics and Prosthodontics ought to cause hearing decrement with the aid of using continual excessive frequency sounds created by dental equipments.

\section{METHODS}

This study involved 38 dentists from the specialities of Periodontics, Conservative Dentistry and Endodontics, and Prosthodontics who were subjected to noise during operating for 6 hours per day and 38 medical professionals who were matched served as a control group. Three audiometric examinations included an otoscopic exam; tympanometry and pure tone audiometry were performed by the participants.

\section{RESULTS}

According to the data, $15.8 \%$ of dentists and $2.6 \%$ of the control group suffered from loss of hearing. In the pure tone audiometry test, there was no substantial difference between the two groups; however, the qualitative analysis showed that the dentists' group had a greater percentage of hearing loss than their control counterparts. In the pure tone audiometry test, there was a statistically significant difference between the specialists from periodontics, conservative dentistry and endodontics, and prosthodontics $(\mathrm{P}=0.005)$.

\section{CONCLUSIONS}

Noise from dental clinics has been shown to cause hearing problems, with the left ear being affected when compared to that of the right; again, these problems aren't serious. Dentists were common among noise-induced hearing impairment and periodontic specialists than conservative dentistry and endodontics, and prosthodontic specialists than the control group,

\section{KEY WORDS}

Dental Professionals, Long Term Exposure, Noise-Induced Hearing Loss, Pure Tone Audiometry.
Corresponding Author:

Dr. Suryakanth Malgikar,

Reader, Department of Periodontology,

Kamineni Institute of Dental Sciences,

Narketpally, Nalgonda Dist.-508254,

Telangana, India.

E-mail: drmalgikarsuryakanth@gmail.com

DOI: $10.14260 /$ jemds/2021/745

How to Cite This Article:

Surakanti JR, Guntakandla VR, Raga P, et al. Dentist's hub bub - a cross sectional study on impact of long-term occupational noise exposure on hearing potential among dental practitioners. J Evolution Med Dent Sci 2021;10(43):3676-3682, DOI: 10.14260/jemds/2021/745

Submission 08-05-2021,

Peer Review 08-10-2021,

Acceptance 16-10-2021,

Published 25-10-2021.

Copyright (C) 2021 Jayaprada Reddy Surakanti et al. This is an open access article distributed under Creative Commons Attribution License [Attribution 4.0 International (CC BY 4.0)] 


\section{BACKGROUND}

Dental professionals in dental settings are exposed to occupational hazards such as radiation and noise. ${ }^{1}$ Noise intensity is measured in decibels $(\mathrm{dB}) .^{2}$ Several sources in day today dental setups such as (e.g., sonic and ultrasonic scalers, high volume suction, handpieces, trimmers used for models and compressors) and non - dental sources such as (e.g., air conditioner, phone ring and workplace music played at loud volume) noise is created. Noise exposure of dental equipment's for many years regularly may lead to noiseinduced hearing loss (NIHL). There are several factors that are contributing to NIHL such as the amount of noise exposure over time, the amount of exposure every day, period of exposure, average sound level, the peak intensity levels of loud sounds, the frequency spectrum of sound, individual's age, physical condition, and also the operating environment.3,4 The recommended noise exposure by National Institute for Occupational Safety and Health (NIOSH) is eighty-five decibels $(\mathrm{dB})$ at forty hours per week. ${ }^{5}$ Among directives for specialized dental devices, ISO standard 7785 for high-speed handpieces specifies that noise levels created ought to be not up to sixty - five decibels (dB) and never exceed eighty decibels (dB).6,7 The purpose of the present study was to identify noise-induced hearing loss in dental practitioners in Tertiary Health Care Institute, operating within the Department of Conservative Dentistry and Endodontics, Periodontics and Prosthodontics wherever the noise generating instruments were used frequently.

\section{METHODS}

The present study was carried out at a single centre from May 2019 to January 2020. A total of 90 participants were enrolled in the study. The institutional ethical committee approved the study (Reg. No: IEC / 2019/21).

\section{Patient Selection Criteria}

The potential participants were enrolled in the study directly personally to clarify the consequences of instrument noise on hearing. The entire procedure was explained to the willing participants and were then asked to sign the written consent form before receiving the audiometric examination.

\section{Inclusion Criteria}

- $\quad$ Age group 35 - 50 years.

- Dental practitioners practising dentistry for a minimum of 10 years and an average exposure to occupational noise for 6 hours per day.

- Medical professionals who were not exposed to noise during their work hours.

\section{Exclusion Criteria}

- Non-occupational noise exposure for more than 3 hours $^{8}$

- Use of hearing protection device

- Hypertension and diabetes mellitus
- Chronic ear disease history

- History of trauma to ear, sensorineural hearing loss, ototoxicity drugs, ear surgery, hereditary factors if any, cold, cough/ear blockage in the previous week

- Radiation or Chemotherapy.

\section{Sample Size}

A total of 76 individuals satisfying the inclusion and exclusion criteria were enrolled in the study. The individuals were divided into two groups. Group I included thirty-eight dentists working in specialities conservative dentistry and endodontics, periodontics and prosthodontics and Group II included thirty-eight medical professionals who were matched. Matching was done based on whether or not the participants were smokers or non-smokers, their age and gender.

\section{Sample Design}

The data collected included age group (35-38, 39-42, 43-46 and 47-50 years of age), both genders, years of practice (1012 or $\geqslant 13$ years), number of days of exposure in a week $(3,4$, 5 , or 6 days), length of exposure to loud noise per week ( $\leqslant 18-27$ hours, $28-36 \mathrm{hrs,} \mathrm{or} \geqslant 37 \mathrm{hrs}$ ), specialisation (Conservative Dentistry \& Endodontics, Periodontics, and Prosthodontics), and right-handed or left-handed dentists (Table 1).

\section{Study Design \\ Audiological Evaluation \\ Pure tone audiometry}

Hearing threshold for all the participants was done by audiological testing. Before audiological testing, the enrolled participants were sent to otoscopic examination and the procedure was explained to the participants (Figure 1A) that was done by employing a Heine mini - 3000 otoscopes. Pure tone audiometry (Digital audiometer CLASSIC - I 01708563) was done to all or any participants. The audiometer (Figure 1B) was calibrated on an everyday basis and in accordance with the International Standards Organization (ISO Protocol, 19 389, 1991). A soundproof room was used for the puretone test. (Figure 1C). The participants were asked to pay attention to pure tone beeps starting from simple sounding to just imperceptible sound levels, and inform the examiner once these pulses were perceived (Figure 1D). The loudness of sound was measured in decibels $(\mathrm{dB})$ and the air conduction hearing thresholds were measured at the subsequent frequencies: $250 \mathrm{~Hz}, 500 \mathrm{~Hz}, 750 \mathrm{~Hz}$, and 1,000 Hz through $8,000 \mathrm{~Hz}$, to determine if the patient had a normal range of hearing levels (25 decibels or lower at $250-8,000$ $\mathrm{Hz}$ ). Hearing thresholds over $25 \mathrm{~dB}$ in these frequencies are usually thought of as abnormal (Figure 1E). This audiological analysis test was performed by a licensed audiologist from the ENT Department. 



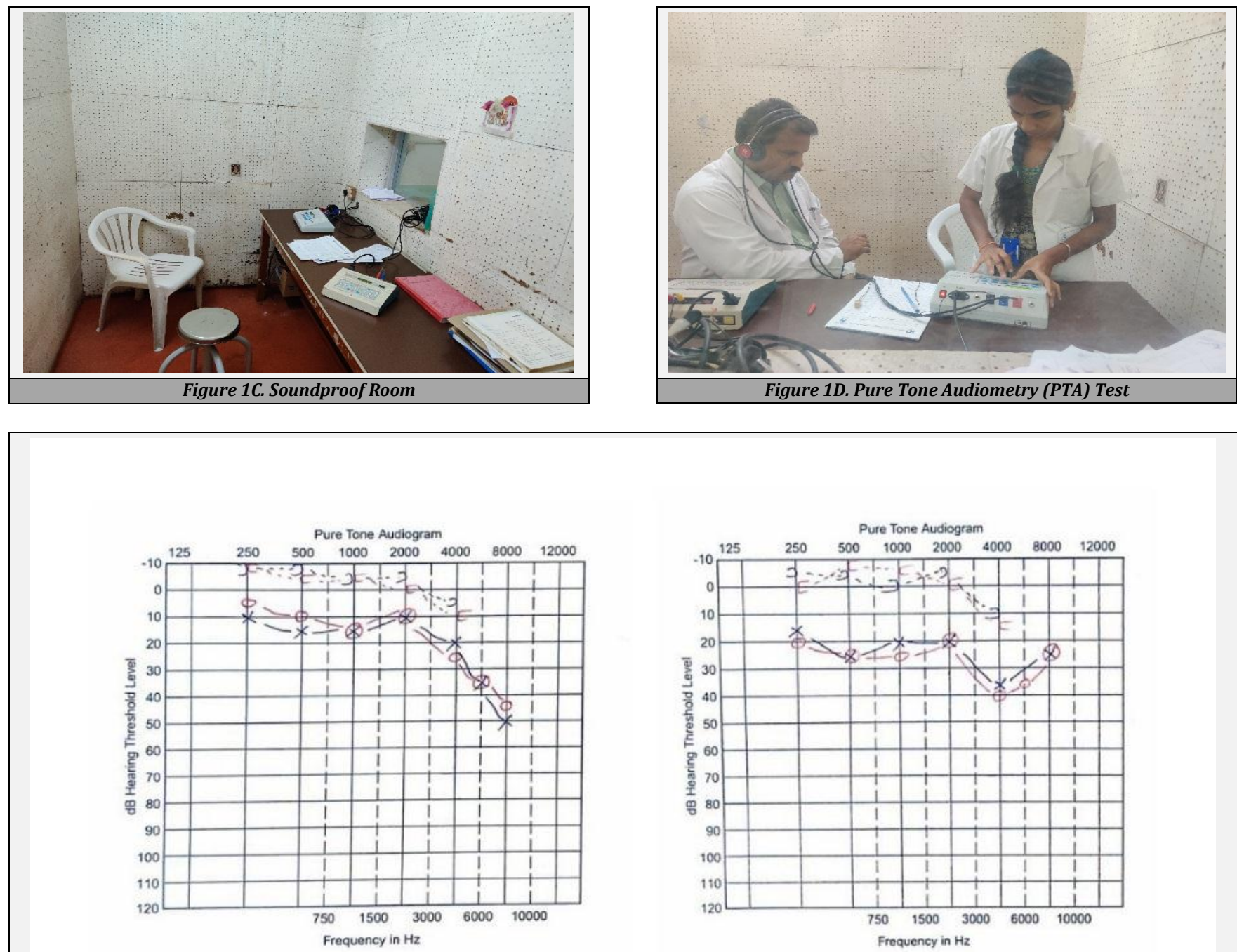

Figure 1E. Audiograms in the Right and Left Ear with Findings Greater than $25 \mathrm{~dB}$ in High Frequencies

- Normal hearing $(N)$ : hearing threshold levels better than or equal to $15 \mathrm{~dB} \mathrm{HL}$ at all measured frequencies (i.e, 0.5 . $1,2,3,4,6,8 \mathrm{kHz}$ ),

- Notch moderate (NM): maximum threshold level of 3,4, and $6 \mathrm{kHz}$ between 15 and $20 \mathrm{~dB}$ poorer than the puretone average of thresholds at $0.5,1$ and $2 \mathrm{kHz}$ and at least $10 \mathrm{~dB}$ poorer than the threshold level at $8 \mathrm{kHz}$. This is similar to Niskar et al. (2001) criterion of a noise notch in adolescents.

- Notch profound (NP): similar to NM, but maximum threshold level of $3,4,6 \mathrm{kHz}$ at least $25 \mathrm{~dB}$ poorer than the pure-tone average of thresholds at $0.5,1$ and $2 \mathrm{kHz}$.

- Sloping loss (SL): maximum threshold level of 3, 4, $6 \mathrm{kHz}$ at least $5 \mathrm{~dB}$ poorer than the pure-tone average of thresholds at $0.5,1$ and $2 \mathrm{kHz}$ and threshold level at $8 \mathrm{kHz}$ at least $5 \mathrm{~dB}$ poorer than the maximum threshold level at 3,4 , and $6 \mathrm{kHz}$.

- Flat loss (FL): audiograms which do not fall into the above mentioned categories, with no hearing thresholds exceeding $30 \mathrm{~dB}$ at all measured frequencies.

- Rest (R): all audiograms that do not match the characteristics of the above described categories. 


\section{Statistical Analysis}

For Windows, the analysis was carried out using IBM SPSS (Statistical Social Sciences Package, Version 20.0, SPSS Inc., Chicago, IL, United States). To conduct power analysis and assess the appropriate sample size, the 3 Power G3.1 program (G*Power: Statistical Power Analyses Heinrich Heine - University Dusseldorf, Dusseldorf, Germany) was used. Wilcoxon test was used to assess if the pure tone audiometry of the test group and the control group was significantly different. The level of significance was $\leq 0.05$. The quality analysis of pure tone audiometry findings was carried out based on Jansen et al. ${ }^{9}$ characterization parameters, used by musicians of symphony orchestras as part of the investigation of noise-induced hearing loss. They adopted a very strict standard listening requirement and precise guidelines for the noise level when present (Figure 2).

\section{RESULTS}

The present observational study was done at a single centre. All the participants were between 35 - 50 years. Twentythree (61\%) were males and fifteen (39\%) were females (Table 1). Six participants in group I (15.8\%) and one participant in group II (2.6\%) had a sensorineural hearing impairment. There was no variation between the 2 groups in terms of NIHL combined in each ear or the left and right ears individually (Table 2A). Once the additional rigorous criteria of fifteen-decibel hearing loss (HL) 9 were applied, the prevalence of hearing loss was twenty-nine participants in group I (76 \%) and twenty - three participants in group II (60 $\%)$. No important distinction was noticed in each of the groups within the pure tone audiometry results at the subsequent frequencies: five hundred $\mathrm{Hz}$, one $\mathrm{kHz}$, two $\mathrm{kHz}$, four $\mathrm{kHz}$, six $\mathrm{kHz}$, and eight $\mathrm{kHz}$.

\begin{tabular}{|c|c|c|}
\hline \multicolumn{3}{|c|}{ Population figures $\mathrm{N}^{*}=38(\%)$} \\
\hline \multirow{2}{*}{ Gender } & Female & 15 (39.47) \\
\hline & Male & $23(60.52)$ \\
\hline \multirow{4}{*}{ Age (years) } & $35-38$ & $17(44.73)$ \\
\hline & $39-42$ & $11(28.94)$ \\
\hline & $43-46$ & $6(15.78)$ \\
\hline & $47-50$ & $4(10.52)$ \\
\hline \multirow{4}{*}{$\begin{array}{c}\text { Weekly } \\
\text { working days }\end{array}$} & 3 & $2(5.26)$ \\
\hline & 4 & $11(28.94)$ \\
\hline & 5 & $19(50)$ \\
\hline & 6 & $6(15.78)$ \\
\hline \multirow{3}{*}{$\begin{array}{l}\text { Weekly working } \\
\text { hours (h) }\end{array}$} & $\leqslant 18-27$ & $13(34.21)$ \\
\hline & $28-36$ & $11(28.94)$ \\
\hline & $\geqslant 37 \mathrm{~h}$ & $14(36.84)$ \\
\hline \multirow{2}{*}{ Years of expertise } & $10-12$ & $19(50)$ \\
\hline & $\geqslant 13$ & $19(50)$ \\
\hline \multirow{3}{*}{ Speciality } & Conservative dentistry and endodontics & $13(34.21)$ \\
\hline & Periodontics & $14(36.84)$ \\
\hline & Prosthodontics & $11(28.94)$ \\
\hline \multirow[b]{2}{*}{ Handiness } & Right - handed & $37(97)$ \\
\hline & Left - handed & $1(3)$ \\
\hline \multicolumn{3}{|c|}{ Table 1. Dentists' Population Figures } \\
\hline
\end{tabular}

\begin{tabular}{|c|c|c|c|c|c|}
\hline \multirow{3}{*}{$\begin{array}{l}\text { Dentist's } \\
\text { Ear }\end{array}$} & \multirow{3}{*}{$\begin{array}{l}\text { Dentist } \\
\left(N^{*}=38\right)\end{array}$} & \multicolumn{4}{|c|}{ Pure Tone Audiometry } \\
\hline & & \multicolumn{2}{|c|}{ Low Frequency } & \multicolumn{2}{|c|}{ High Frequency } \\
\hline & & Std & Mean & Std & Mean \\
\hline Right & 38 & 5.96077 & 11.2916 & 6.92840 & 11.6429 \\
\hline Left & 38 & 6.24268 & 9.9379 & 8.00434 & 11.5600 \\
\hline $\begin{array}{c}\text { Both ears } \\
\text { (Right and Left) }\end{array}$ & 38 & 6.10070 & 10.6147 & 7.43577 & 11.6014 \\
\hline \multicolumn{6}{|c|}{$\begin{array}{c}\text { Table 2b. For Dentist's, it Depicts Descriptive Statistics of Hearing } \\
\text { Thresholds at Various Frequencies }\end{array}$} \\
\hline
\end{tabular}

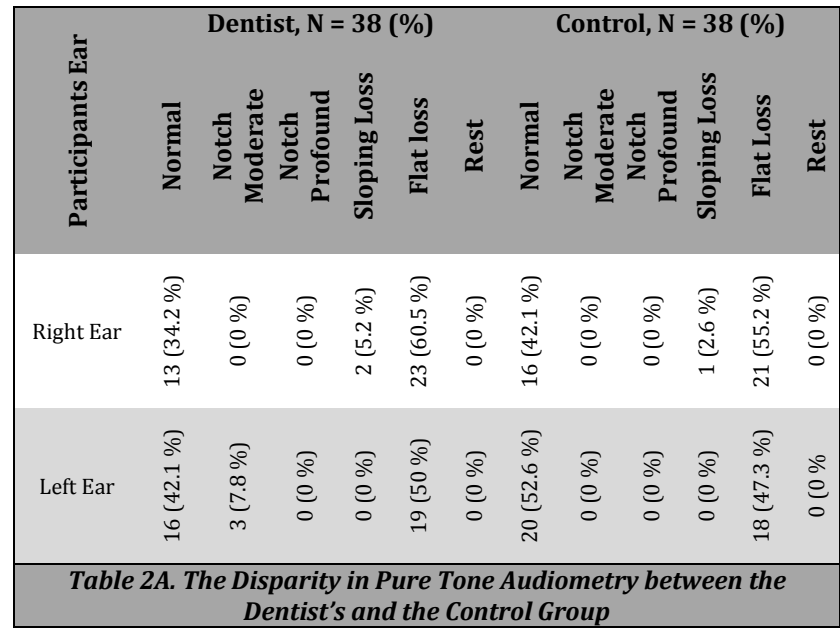

\begin{tabular}{|c|c|c|c|c|c|}
\hline \multirow{3}{*}{$\begin{array}{c}\text { Control's } \\
\text { Ear }\end{array}$} & \multirow{3}{*}{$\begin{array}{c}\text { Control } \\
\left(N^{*}=38\right)\end{array}$} & \multicolumn{4}{|c|}{ Pure Tone Audiometry } \\
\hline & & \multicolumn{2}{|c|}{ Low Frequency } & \multicolumn{2}{|c|}{ High Frequency } \\
\hline & & Std & Mean & Std & Mean \\
\hline Right & 38 & 5.00613 & 10.4055 & 4.85405 & 10.0229 \\
\hline Left & 38 & 5.45226 & 8.4011 & 7.11611 & 9.2416 \\
\hline $\begin{array}{c}\text { Both ears } \\
\text { (right and left) }\end{array}$ & 38 & 5.29593 & 9.4033 & 6.06303 & 9.6322 \\
\hline
\end{tabular}

\begin{tabular}{|c|c|c|c|c|}
\hline \multirow{2}{*}{$\begin{array}{l}\text { Participants } \\
\text { Ear }\end{array}$} & \multirow{2}{*}{$\begin{array}{l}\text { Dentist } \\
\left(N^{*}=38\right)\end{array}$} & \multirow{2}{*}{$\begin{array}{l}\text { Control } \\
\left(N^{*}=38\right)\end{array}$} & \multicolumn{2}{|c|}{$\begin{array}{c}\text { Pure Tone Audiometry } \\
\text { The } \mathrm{P}^{*} \text { Value of the Affected } \\
\text { Frequencies }\end{array}$} \\
\hline & & & $\begin{array}{c}\text { Low } \\
\text { Frequency }\end{array}$ & $\begin{array}{c}\text { High } \\
\text { Frequency }\end{array}$ \\
\hline Right & 38 & 38 & 0.387 & 0.321 \\
\hline Left & 38 & 38 & 0.293 & 0.217 \\
\hline $\begin{array}{c}\text { Both ears } \\
\text { (Right and Left) }\end{array}$ & 38 & 38 & 0.173 & 0.132 \\
\hline \multicolumn{5}{|c|}{$\begin{array}{c}\text { Table 3. Audiogram Findings for Each Group were Characterized Usin } \\
\text { Parameters advised by Jansen et al. } 9 \text { for Pure Tone Audiograms }\end{array}$} \\
\hline
\end{tabular}

The mean values for each dentist and their control counterparts are seen in Tables 2B and 2C for the pure-tone audiometry test. Dentists operating within the speciality of periodontics were most established in terms of noise-induced hearing loss than in conservative dentistry and endodontics, and prosthodontics ( $\mathrm{P} \leq 0.05)$. Dentists had $60.5 \%$ flat loss whereas $5.2 \%$ of the exhibited sloping loss in the right ear when compared to the left ear, $50 \%$ had a flat loss and $7.8 \%$ had a moderate notch respectively. On the opposite hand, $42.1 \%$ of the control group showed normal hearing within the right ear, and $52.6 \%$ had normal hearing in the left ear (Table 3). Jansen et al. ${ }^{9}$ in their qualitative analysis showed different patterns among the dentists as compared to their control.

\section{DISCUSSION}

Exposure to noise levels higher than eighty-five $\mathrm{dB}$ without any form of hearing aids result in hearing impairment.10-12 Hence, in the dental setups the noise generated mustn't be overlooked. ${ }^{13}$ High-speed rotary handpieces, high-velocity suctions, sonic and ultrasonic scalers in the dental clinic may cause hearing damage to ears by their sounds. ${ }^{14} 15.8 \%$ of hearing impairment was seen among dentists using the pure tone audiometry test. The intensity of the sound and length of exposure is a risk to the dentist. ${ }^{14,15}$ Dental practitioners 
exhibited around similar incidences of symptoms; i.e., $16.6 \%$ tinnitus, $14.7 \%$ speech discrimination difficulties and $63 \%$ had issues with speech discrimination within the presence of background noise in Saudi Arabia. ${ }^{16}$ According to Altinoz et al. ${ }^{17}$ dentists who practice in noisy environments should avoid engaging in disruptive tasks directly after work. The authors claimed that "the hearing capacity of the ear starts to recover when it relaxes."

According to the literature, the incidence of noise-induced hearing impairment in dental practitioner's ranges from seven to sixteen percent. ${ }^{18-20}$ The Khaimook et al. ${ }^{21}$ analysis has shown that the incidence of hearing loss among dental personnel is $17.7 \%$. But, compared to the control group there were no major variations. The danger of developing noiseinduced hearing loss among the dental practitioners will be attenuated by encouraging them to follow the advice of the ADA Council on dental materials and devices, 22 which embrace the following: Noise attenuation steps ought to be targeted in 3 areas: best rotary instrumentation management, dodging of ambient noise levels in the operatory, and personal safety by the use of earplugs. Annual audiometry tests should be done by dentists. Manufacturers are being suggested to increase potency by reducing the quantity of noise created by high-speed dental handpieces. Furthermore, as old and tired equipment wears out, vibration increases, leading to higher sound levels and emphasizing the importance of standard servicing and replacement. ${ }^{23}$ The curriculum in several dental schools should embrace education regarding the various occupational hazards. ${ }^{24}$

\section{CONCLUSIONS}

There is a potential risk for developing hearing problems through the noise from dental clinics, which had a larger impact on the left ear compared to the right. Dentists had noise-induced hearing loss compared to medical professionals. Among the dentist's, the practitioners from the periodontics speciality exhibited significant hearing loss compared to conservative dentistry and endodontics and prosthodontics.

\section{Limitations of the Study}

Limitations of the present study are many variables in hearing loss, smoking, ethnicity, dental professionals, noises from several dental equipments, and left-handed dentists versus right, was restricted because of a less sample size. As a result, further trials with a larger sample size are needed to investigate the impact of years of experience, working hours per week, smoking, and gender on hearing loss, as well as to determine which members of the dental staff are the most affected by noise exposure.

Data sharing statement provided by the authors is available with the full text of this article at jemds.com.

Financial or other competing interests: None.

Disclosure forms provided by the authors are available with the full text of this article at jemds.com.

\section{REFERENCES}

[1] Leggat PA, Kedjarune U, Smith DR. Occupational health problems in modern dentistry: a review. Ind Health 2007;45(5):611-21.

[2] Saini R, Saini G, Saini S, et al. Dental practice and perilous auditory effect as occupational hazard. Noise Health 2010;12(46):56.

[3] Setcos JC, Mahyuddin A. Noise levels encountered in dental clinical and laboratory practice. Int J Prosthodont 1998;11(2):150-7.

[4] Bahannan S, el-Hamid AA, Bahnassy A. Noise level of dental handpieces and laboratory engines. J Prosthet Dent 1993;70(4):356-60.

[5] Maximum noise permissible limits in dental operatory, 1998.

http://www.cdc.gov/niosh/topics/noise/stats.html.

[6] Standard 7785 - 1. Part 1: High - speed Air Turbine Hand pieces in Dental Hand pieces International Standardization Organization Geneva 1997. http://www.ada.org/sections/scienceAndResearch/pdfs /0707_hsair_testmethods.pdf.

[7] Dyson JE, Darvell BW. Dental air turbine handpiece performance testing. Aust Dent J 1995;40(5):330-8.

[8] Torre P. Young adults' use and output level settings of personal music systems. Ear Hear 2008;29(5):791-9.

[9] Jansen EJ, Helleman HW, Dreschler WA, et al. Noise induced hearing loss and other hearing complaints among musicians of symphony orchestras. Int Arch Occup Environ Health 2009;82(2):153-64.

[10] Berger EH. Hearing protector performance: how they work-and-what goes wrong in the real world. E - A - R Log Series of Technical Monographs on Hearing and Hearing Protection 1980:1-4.

[11] Dobie RA. Industrial audiometry and the otologist. Laryngoscope 1985;95(4):382-5.

[12] World Health Organization. Prevention of deafness and hearing impairment: report by the Director-General. Thirty Ninth World Health Assembly. World Health Organization 1986:31-8.

[13] Bali N, Acharya S, Anup N. An assessment of the effect of sound produced in a dental clinic on the hearing of dentists. Oral Health Prev Dent 2007;5(3):187-91.

[14] Kumar PR, Sharma P, Kalavathy N, et al. Hearing damage and it's prevention in dental practice. Journal of Dental Sciences and Research 2011;2(2):32-5.

[15] Daud MK, Noh NFM, Sidek DS, et al. Screening of dental staff nurses for noise induced hearing loss. B-ENT 2011;7(4):245-9.

[16] Alwazzan K, Alqahtani M, Alshethri S, et al. Hearing problems among dental personnel. JPDA 2005;14:210-4.

[17] Altinoz HC, Gokbudak R, Bayraktar A, et al. A pilot study of measurement of the frequency of sounds emitted by high-speed dental air turbines. J Oral Sci 2001;43(3):189-92.

[18] Dube KJ, Ingale LT, Ingale ST. Hearing impairment among workers exposed to excessive levels of noise in ginning industries. Noise Health 2011;13(54):348-55.

[19] Engdahl B, Tambs K. Occupation and the risk of hearing impairment -- results from the nord - trondelag study on hearing loss. Scand J Work Environ Health 2010;36(23):250-7. 
[20] Krishnamurti S. Sensorineural hearing loss associated with occupational noise exposure: effects of agecorrections. Int J Environ Res Public Health 2009;6:88999.

[21] Khaimook W, Suksamae P, Choosong T, et al. The prevalence of noise-induced occupational hearing loss in dentistry personnel. Workplace Health Saf 2014;62(9):357-60.
[22] Noise control in the dental operatory. Council on dental materials and devices. J Am Dent Assoc 1974;89(6):1384-5.

[23] Coles RR, Hoare NW. Noise-induced hearing loss and the dentist. Br Dent J 1985;159(7):209-18.

[24] Al Shayea Eman I. Prevalence of noise induced hearing loss and other associated risk factors among saudi dental professionals. J Res Med Dent Sci 2020;8(4):17-23. 